\title{
Magnitude of post-operative mortality and associated factors among patients who underwent surgery in Wolaita Sodo teaching and referral hospital, SNNPR region, Ethiopia
}

\author{
Tiwabwork Tekalign, Habtamu Balta, Lolemo Kelbiso
}

School of Nursing, College of Health Science and Medicine, Wolaita Sodo University, Wolaita Sodo, Ethiopia.

\section{Email Address:}

Tiwabwork T: tiwabworkt@gmail.com; Habtamu B :habtena16@gmail.com; Lolamo K: lolemo2001@gmail.com

\begin{abstract}
Background: Each year 4.2 million people around the world die within 30 days of surgery and postoperative deaths account for $7.7 \%$ of all deaths. So this study aimed to asses' magnitude of postoperative mortality and associated factors among patients who underwent surgery in Wolaita Sodo University Teaching referral Hospital.

Method: Retrospective cross sectional design was carried out from April 15-30 2019. Card review was done on 384 participants by using Systematic sampling technique. Entered to Epi Data; exported to SPSS for analysis. Variables with p-value $<0.25$ in bivariate analysis were entered to multivariate logistic regression. Statistical significance is determined at p-value $<$ 0.05 .

Results: The magnitude of postoperative mortality was $5.7 \%$. Using surgical check list (AOR $=0.18 ; 95 \%$ CI 0.05 to 0.61 ), having comorbid condition ( $\mathrm{AOR}=4.45 ; 95 \% \mathrm{CI} 1.39$ to 14.19), and don't having blood transfusion ( $\mathrm{AOR}=0.07 ; 95 \% \mathrm{CI}$ 0.02 to 0.22$)$ and general anesthesia (AOR $=4.37 ; 95 \%$ CI 1.17 to 16.30$)$ are factors of post-operative mortality.

Conclusion: The magnitude of postoperative mortality was high. Surgical check list, comorbidity, blood transfusion and general anesthesia are factors. The hospital should encourage using of surgical check list and work on comorbid patients to decrease the mortality.

Keywords: Magnitude, mortality, surgery, post-operative, Wolaita.

DOI: https://dx.doi.org/10.4314/abs.v21i4.42

Cite as: Tekalign T, Balta H, Kelbiso L. Magnitude of post-operative mortality and associated factors among patients who underwent surgery in Wolaita Sodo teaching and referral hospital, SNNPR region, Ethiopia. Afri Health Sci. 2021;21(4):1842-8. https:/ / dx.doi.org/ 10.4314/ ahs.v21i4.42
\end{abstract}

\section{Introduction}

Operative mortality refers to any death, regardless of cause, occurring within 30 days after surgery, in or out of the hospital, and after 30 days during the same hospitalisation subsequent to the operation ${ }^{1}$.

Surgery is an essential component of health care systems and currently the overall burden of disease that may be cured, palliated or treated with surgical intervention is large and rapidly growing ${ }^{2}$.

\section{Corresponding author:}

Tiwabwork Tekalign,

School of Nursing, College of Health Science

and Medicine, Wolaita Sodo University, Wolaita

Sodo, Ethiopia.

Email: tiwabworkt@gmail.com,

emgelila2123@gmail.com
Globally, 313 million surgical procedures are performed each year. In low- and middle-income countries (LMICs), $60 \%$ of surgical operations are performed for patients who need emergency surgery, But 143 million additional surgical procedures are needed each year to save lives and prevent disability ${ }^{3,4}$.

Surgical procedure is not risk-free and it always comes with a risk of death due to the procedure or the anaesthesia that is given during the procedure and also due to postoperative complications with considering patient condition at the time of surgery ${ }^{5,6}$.

Surgical care affects the lives of millions of people. Studies indicate that complications following surgery result in disability or a prolonged hospital stay in 3-25\% of hospitalised patients, depending on the complexity of surgery and the hospital setting, In fact of this 28$32 \%$ of the global burden of disease can be attributed to surgically treatable conditions ${ }^{7,8}$. 
Although each year, 4.2 million people around the world die within 30 days of surgery, and postoperative deaths account for $7.7 \%$ of all deaths globally, half of these occur in LMICs ${ }^{9}$. A study conducted in St Paul's Hospital Millennium Medical College, Addis Ababa, showed that surgical mortality rate was $3.41 \%{ }^{10}$. Besides in Ethiopia, both a shortage of surgeons and surgical care make the problem worse $\mathrm{e}^{11,12}$.

Currently, surgical mortality is considered as one indicator of quality of care, so this study aims to assess magnitude of postoperative mortality and associated factors among patients who underwent surgery in Wolaita sodo university teaching and referral hospital

\section{Methods and material}

\section{Study setting, design and population}

Wolaita Sodo University Teaching Hospital (WSUTH) is located in South Nations Nationalities and People Region States (SNNPRS), Ethiopia. The hospital was established in 1928 and serves 2 million people. Retrospective cross sectional study design was carried out. All and selected medical records of patients who underwent surgery in year of 2008-2010 E.C in WSUTRH were taken as a source population and study population respectively.

\section{Variables of the study}

In this study magnitude of mortality is considered as dependent variable whereas Socio-demographic Characteristics (Age, Sex, Occupation, Marital status, place of residence) and general health profile (types of surgery, types of anesthesia, length of stay, surgical check list, blood transfusion, and comorbidity) were independent variables.

\section{Eligibility criteria}

All medical record of patient who underwent surgery during the study period were included in the study while incomplete medical record were excluded from the study

\section{Sample size determination}

The sample size was determined by using a single population proportion formula. The following assumptions were applied: p, prevalence of $50 \%$ (since there is no locally conducted study), $\mathrm{d}$ is the expected margin of error $(5 \%), Z$, the standard score corresponding to a
$95 \%$ confidence interval and $\alpha$, the risk of rejecting the null hypothesis (0.05). Accordingly the required sample size became 384 .

\section{Sampling technique}

A total of 6623 patients underwent surgery in year of 2008-2010 E.C in WSUTRH. From them using systematic sampling technique in every seventeenth interval, a total of 384 patient cards were identified and traced using registration number.

Data collection procedure/instruments

Data were collected by using pretested checklist from April 1-30 2019. All the variables of interest were assessed accordingly and the checklist was prepared in English. Those who have diploma in nursing were participated in the data collection process. Training was given to the data collectors.

\section{Data Analysis}

Epi data version 3.5.1 used for data entry and SPSS version 21 was used for analysis. Descriptive statistics were computed to determine frequencies and summarize statistics. Variables having P-value $<0.25$ in bivariate analysis were selected as a candidate for multivariate logistic regression. Finally $\mathrm{P}$ value $<0.05$, at $95 \%$ confidence interval was declared as statistically significant.

\section{Data quality control}

Orientation and appropriate supervision were done to data collectors by supervision made on daily basis by the principal investigator. And completeness and consistency were checked every day during data collection. Pre- test was done on 5\% of the total sample size in the same hospital on patient records before the study period. Appropriate modifications were made after analyzing the pre-test result before the actual data collection.

\section{Results}

\section{Socio-Demographic Characteristics}

A total of 384 patient medical records were enrolled in this study. Out of the total respondents, a majority 182(47.4\%) were in age between21-40. More than half $200(52.1 \%)$ and $216,56.3 \%$ of participants were of female and living in rural respectively. Two hundred and seventy four $(71.4 \%)$ were married and $238(62.0 \%)$ were unemployed (see Table 1). 
Table 1: socio-demographic characteristics of study subjects undergone surgery in WSUTRH in last from 2008-2010 E.C ( $\mathrm{n}=384)$

\begin{tabular}{|c|c|c|}
\hline Variables & Category & Frequency (\%) \\
\hline \multirow{4}{*}{ Age of participant } & $0-20$ years & $73(19.0)$ \\
\hline & 21-40 years & $182(47.4)$ \\
\hline & 41--60 years & $84(21.9)$ \\
\hline & $>60$ years & $45(11.7)$ \\
\hline \multirow{2}{*}{ Residence } & Rural & $216(56.3)$ \\
\hline & Urban & $168(43.8)$ \\
\hline \multirow{2}{*}{ Sex } & Male & 184(47.9) \\
\hline & Female & $200(52.1)$ \\
\hline \multirow{3}{*}{ Marital status of patients } & Single & $75(19.5)$ \\
\hline & Married & $274(71.4)$ \\
\hline & Others $^{1}$ & $35(9.1)$ \\
\hline \multirow{2}{*}{ Occupational status } & Employed & $146(38.0)$ \\
\hline & \begin{tabular}{|l} 
Unemployed \\
\end{tabular} & $238(62.0)$ \\
\hline
\end{tabular}

Others ${ }^{1}$ - divorced, widowed

\section{General Health Profile of Study Participants}

Respectively, 354(92.2\%) and $340(88.5 \%)$ of the participants didn't have a postoperative surgical checklist and comorbid conditions. Three fourth 288(75.0\%) and $61(15.9 \%)$ of participants stayed in the hospital for less than a week and have blood transfusions history, respectively. Two hundred and sixty two (68.2\%) u1 'nderwent emergency surgery, and more than half $>1(52.3 \%$ ) received regional anaesthesia (see Table 2 ).

Table 2: General health profile of study participants who come for surgery in WSUTRH in last from 2008-2010 E.C $(n=384)$

\begin{tabular}{|c|c|c|}
\hline Variables & Category & Frequency (\%) \\
\hline \multirow[t]{2}{*}{ Surgical check list } & Yes & $30(7.8)$ \\
\hline & No & $354(92.2)$ \\
\hline \multirow[t]{2}{*}{ Comorbidity } & Yes & $44(11.5)$ \\
\hline & No & $340(88.5)$ \\
\hline \multirow[t]{2}{*}{ Length of stay } & $k=1$ week & $288(75.0)$ \\
\hline & $>1$ week & $96(25.0)$ \\
\hline \multirow[t]{2}{*}{ Blood transfusion } & Yes & $61(15.9)$ \\
\hline & No & $323(84.1)$ \\
\hline \multirow[t]{2}{*}{ Type of surgery } & \begin{tabular}{|l} 
Elective \\
\end{tabular} & \begin{tabular}{|l|}
$122(31.8)$ \\
\end{tabular} \\
\hline & Emergency & $262(68.2)$ \\
\hline \multirow[t]{2}{*}{ Type of anesthesia } & Regional & $201(52.3)$ \\
\hline & General & 183(47.7) \\
\hline
\end{tabular}


Magnitude of Postoperative Mortality

According to this study magnitude of postoperative mortality was $5.7 \%$.

\section{Associated Factors of Postoperative Mortality}

There were 9 variables in binary logistic regression that had a p-value of less than 0.25 and became a candidate for multiple logistic regressions. In multiple logistic regressions, four variables were significantly associated with postoperative mortality, with $\mathrm{P}$ value $<0.05$ (see Table 3).
Those having surgical check list were $82 \%$ less likely to die postoperatively (AOR $=0.18 ; 95 \%$ CI 0.05 to 0.61 ) than those who didn't have a postoperative surgical checklist. Those having comorbid conditions were four times to die post-operatively $(\mathrm{AOR}=4.45 ; 95 \% \mathrm{CI} 1.39$ to 14.19) than their counterparts. Those didn't have blood transfusion were $93 \%$ less likely to die post-operatively (AOR $=0.07 ; 95 \%$ CI 0.02 to 0.22$)$ than those who have blood transfusions. Those patients had given general anaesthesia were four times to die postoperatively $(\mathrm{AOR}=4.37$; 95\% CI 1.17 to 16.30$)$ than those who had given regional anaesthesia.

Table 3: bivariate and multivariate analysis of socio demographic and General health profile of study participants who underwent surgery in WSUTRH from 2008-2010 E.C ( $n=384)$

\begin{tabular}{|c|c|c|c|c|c|c|}
\hline \multirow[t]{2}{*}{ Variable } & \multirow[t]{2}{*}{ Category } & \multicolumn{2}{|c|}{ Postoperative mortality } & \multirow[t]{2}{*}{ C OR ,95\%CI } & \multirow[t]{2}{*}{ P- value $(<0.25)$} & \multirow[t]{2}{*}{ AOR,95\%CI } \\
\hline & & Yes & No & & & \\
\hline \multirow[t]{2}{*}{ Occupation } & Employed & $4(2.7 \%)$ & $142(97.3 \%)$ & $0.34(0.11,1.03)$ & 0.152 & $2.58(0.70,9.46)$ \\
\hline & Unemployed & $18(7.6 \%)$ & $220(92.4 \%)$ & 1 & & 1 \\
\hline \multirow{3}{*}{$\begin{array}{l}\text { Marital } \\
\text { status }\end{array}$} & Single & $6(8.0 \%)$ & $69(92.0 \%)$ & 1 & & 1 \\
\hline & Married & $11(4.0 \%)$ & $263(96.0 \%)$ & $0.48(0.17,1.34)$ & 0.070 & $0.81(0.20,3.18)$ \\
\hline & Others & $5(14.3 \%)$ & $30(85.7 \%)$ & $1.91(0.54,6.77)$ & 0.936 & $0.92(0.13,6.29)$ \\
\hline \multirow[t]{2}{*}{ Residence } & Rural & $17(7.9 \%)$ & $199(92.1 \%)$ & 1 & & 1 \\
\hline & Urban & $5(3.0 \%)$ & $163(97.0 \%)$ & $2.78(1.00,7.71)$ & 0.067 & $2.99(0.92,9.68)$ \\
\hline \multirow{2}{*}{$\begin{array}{l}\text { Surgical } \\
\text { check list }\end{array}$} & Yes & $7(23.3 \%)$ & $23(76.7 \%)$ & $6.87(2.55,18.54)$ & 0.006 & $0.18(0.05,0.61)$ \\
\hline & No & $15(4.2 \%)$ & $339(95.8 \%)$ & 1 & & 1 \\
\hline \multirow[t]{2}{*}{ Comorbidity } & Yes & $7(15.9 \%)$ & $37(79.4 \%)$ & $2.44(0.09,0.63)$ & 0.012 & $\begin{array}{l}4.45(1.39, \\
14.19)\end{array}$ \\
\hline & No & $15(4.4 \%)$ & $325(95.6 \%)$ & 1 & & 1 \\
\hline \multirow{2}{*}{$\begin{array}{ll}\text { Length } \\
\text { stay }\end{array}$} & $<=1$ week & $11(3.8 \%)$ & $277(96.2 \%)$ & 1 & & 1 \\
\hline & $>1$ week & $11(11.5 \%)$ & $85(88.5 \%)$ & $0.30(0.12,0.73)$ & 0.523 & $0.68(0.21,2.17)$ \\
\hline \multirow{2}{*}{$\begin{array}{l}\text { Blood } \\
\text { transfusion }\end{array}$} & Yes & $15(24.6 \%)$ & $46(75.4 \%)$ & 1 & & 1 \\
\hline & No & $7(2.2 \%)$ & $316(97.8 \%)$ & $14.7(5.69,38.02)$ & 0.000 & $0.07(0.02,0.22)$ \\
\hline \multirow{2}{*}{$\begin{array}{ll}\text { Type } & \text { of } \\
\text { surgery } & \end{array}$} & Elective & $12(9.8 \%)$ & $110(90.2 \%)$ & 1 & & 1 \\
\hline & Emergency & $10(3.8 \%)$ & $252(96.2 \%)$ & $2.74(1.15,6.55)$ & 0.171 & $2.09(0.72,6.04)$ \\
\hline \multirow{2}{*}{$\begin{array}{l}\text { Type of } \\
\text { anesthesia }\end{array}$} & General & $19(10.4 \%)$ & $164(89.6 \%)$ & $7.64(2.22,26.29)$ & 0.028 & $4.37(1.17,16.30)$ \\
\hline & Regional & $3(1.5 \%)$ & $198(98.5 \%)$ & 1 & & 1 \\
\hline
\end{tabular}




\section{Discussion}

The overall magnitude of postoperative mortality in this study was $5.7 \%$, higher than the studies carried out at Zewditu memorial Hospital, Addis Ababa, (2.82\%), Tikur Anbesa specialized hospital, Addis Ababa (4.5\%), in Japan $(2 \%)$, and Netherlands $(1.85 \%)^{13-15}$. This might be due to a shortage of safe and timely surgical care, as well as the fact that the studied hospital serves a huge catchment area.

However, it was significantly lower than the rate shown by studies conducted in Nigeria $(8.3 \%)$ and United states $(7.0 \%),{ }^{17,18}$. This might be due to variations in study duration, socio-demographic characteristics of participants and urbanisation levels of the study area. Using surgical check list has relationship with postoperative mortality. Those having surgical check list were $82 \%$ less likely to die postoperatively $(\mathrm{AOR}=0.18 ; 95 \%$ CI 0.05 to 0.61 ) than those who didn't have a postoperative surgical checklist.

This finding is consistent with studies done in different parts of the world; this may be an indicator of countries that use a World Health Organization (WHO) surgical safety checklist, as recommended ${ }^{19-23 .}$.

Previous history of comorbidities was significantly associated with postoperative mortality. In this study those patients having comorbid conditions were four times to die post-operatively (AOR $=4.45 ; 95 \%$ CI 1.39 to 14.19$)$ than their counterparts. Different studies also indicated that patients having one or more comorbidities were associated with a high risk of mortality from causes other than surgery and related treatment; even it worsens the effect on vital organs ${ }^{24-26}$.

Blood transfusion has an impact on postoperative mortality. This study indicated that, those didn't have history of blood transfusion were $93 \%$ less likely to die post-operatively ( $\mathrm{AOR}=0.07 ; 95 \%$ CI 0.02 to 0.22 ) than those who have blood transfusions. This finding is consistent with studies conducted in the different parts of the world $2^{4,25}$, and ${ }^{27-30}$.

Possibly, blood transfusion during an operation is an indicator of a complication. However, this is inconsistent with studies conducted in Veterans Affairs medical Centre ${ }^{31}$. A possible explanation may be that blood transfusions are considered critical for patients undergoing major surgery on one or more of their internal organs because of postoperative blood loss was significant for those patients ${ }^{32}$

In this study those patients had given general anaesthe- sia were four times to die postoperatively $(\mathrm{AOR}=4.37$; $95 \%$ CI 1.17 to 16.30 ) than those who had given regional anaesthesia. This is consistent with study conducted America $^{33}$ in which using general anaesthesia is associated with increased postoperative mortality. Surgical procedures which need general anaesthesia by nature are major surgery; association of postoperative death may be related with surgery type in addition to anaesthesia type used.

\section{Conclusion}

According to this study postoperative mortality was high compared to other studies. Using surgical check list, having comorbidity, having blood transfusion and using general anesthesia are predictors.. The hospital should encourage using of surgical check list and work on comorbid patients to decrease the mortality.

\section{Limitation of the study}

The main limitation of this studies its retrospective nature, due to the design we are unable to asses some variables like income, and the type of comorbid condition a patient has.

\section{Abbreviations/acronyms \\ - $\quad$ AOR-Adjusted Odds Ration \\ - CI- Confidence Interval \\ - $\quad$ COD- Crude Odds Ratio \\ - $\quad$ SPSS- Statical Package for Social Science \\ - WSUTH- Wolaita Sodo University Teaching Hospital}

\section{Declaration}

\section{Ethics approval and consent}

Ethical clearance and approval letter to conduct study was obtained from Wolaita Sodo University ethical review committee and a letter of cooperation was taken from the nursing department. Confidentiality of the information was ensured by coding and anonymity was kept.

\section{Consent for publication}

Not applicable.

Availability of supporting data

All data supporting the study is available with the reasonable request.

\section{Competing interests}

The authors declare that they have no conflicts of interest. 


\section{Funding}

The research is not funded.

\section{Authors' contributions}

Conceptualization; - HB, T'T, LK; Formal analysis; - T'T; Funding acquisition; HB, TT, LK; Investigation; - HB, TT, LK; Methodology; - HB, TT, LK; Resources; - HB, TT, LK; Software; - HB, TT, LK; Supervision; - TT, LK; Validation; - TT, LK; Visualization; - TT, LK, HB; Roles/Writing - original draft; - TT, LK, HB; Writing review \&editing; - TT, LK, HB

\section{Acknowledgements}

We would like to express our deepest gratitude to the Wolaita Sodo teaching and referral hospital staffs and the data collectors.

\section{References}

1. Johnson, M.L., Gordon, H.S., Petersen, N.J. et al. Effect of definition of mortality on hospital profiles. (Comment in: Med Care. 2002; 40:1-3 PubMed .) Med Care. 2002; 40: 7-16 PubMed

2. Doruk Ozgediz a, Dean Jamison b, Meena Cherian c, Kelly McQueen The burden of surgical conditions and access to surgical care in low- and middle-income countries. Bulletin of the World Health Organization 2008, 86 (8)

3. Meara JG, Leather AJ, Hagander L, et al. Global Surgery 2030: evidence and solutions for achieving health, welfare, and economic development. Lancet 2015; 386(9993): 569-624. PubMed

4. Mccord C, Ozgediz D, Beard JH, et al.. General surgical emergencies, essential surgery: disease control priorities, vol. 1. 3rd ed. Washington, DC: World Bank; 2016; p. 1-30.

5. Jennifer Whitlock, The Risk of Death from Surgery; The serious risks of surgery 2019 https:// www.verywellhealth.com/what-is-the-risk-of-deathfrom-surgery-3157294

6. Shimada H, Fukagawa T, Haga Y, et al. Does postoperative morbidity worsen the oncological outcome after radical surgery for gastrointestinal cancers? A systematic review of the literature. Ann Gastroenterol Surg. 2017; 1: 11- 23 PubMed

7. Health care in Europe, Ten facts on safe surgery https://healthcare-in-europe.com/en/news/tenfacts-on-safe-surgery.html

8. Global Surgery 2030, evidence and solutions for achieving health, welfare, and economic development REPORT OVERVIEW

9. Nepogodiev D, Martin J, Biccard B, et al.
Global burden of postoperative death. Lancet. 2019; 393(10170):401 PubMed .

10. Dandena, F., Leulseged, B., Suga, Y., \& Teklewold, B. (2020). Magnitude and Pattern of Inpatient Surgical Mortality in a Tertiary Hospital in Addis Ababa, Ethiopia. Ethiopian Journal of Health Sciences, 30(3), 371-376.

11. Derbew, M., Laytin, A.D. \& Dicker, R.A. The surgical workforce shortage and successes in retaining surgical trainees in Ethiopia: a professional survey 2016; Hum Resour Health 14(29) doi:10.1186/s12960-0160126-7

12. Tigistu A. In countries with a shortage of surgeons, other health care workers can fill in the gaps 2017. https://www.statnews.com/2017/08/09/surgeons-shortage-ethiopia/

13. Gebresellassie, H.W., Tamerat, G. Audit of surgical services in a teaching hospital in Addis Ababa, Ethiopia. BMC Res Notes. 12, 678 (2019) doi:10.1186/ s13104-019-4709-y

14. Biluts H, Bekele A, Kottiso B., et al, In-patient surgical mortality in Tikur Anbessa Hospital: A fiveyear review. Ethiop Med J. 2009 ;47(2):135-42.

15. Shidara, Y., Fujita, Y., Fukunaga, S. et al. In-hospital mortality after surgery: a retrospective cohort study in a Japanese university hospital. Springer Plus 5, 680 (2016) doi:10.1186/s40064-016-2279-1

16. Peter G. Noordzij, Don Poldermans, Olaf Schouten, Jeroen J. Bax, Frodo A. G. Schreiner, Eric Boersma; Postoperative Mortality in The Netherlands: A Population-based Analysis of Surgery-specific Risk in Adults. Anesthesiology 2010; 112:1105-1115 PubMed doi: https://doi.org/10.1097/ALN.0b013e3181d5f95c 17. Kato, H., Jena, A. B., \& Tsugawa, Y. (2020). Patient mortality after surgery on the surgeon's birthday: observational study. BMJ , 371 .

18. Ihegihu, C. C., Chianakwana, G. U., Ugezu, T., \& Anyanwu, S. N. C. (2007). A review of in-hospital surgical mortality at the Nnamdi Azikiwe University Teaching Hospital Nnewi, Nigeria. Tropical Journal of Medical Research, 11(2), 26-30

19. Michael Mc. BMJ 2017;357:j1935

20. Alex B., Thomas G.W., William RB., et al A Surgical Safety Checklist to Reduce Morbidity and Mortality in a Global Population. N Engl J Med 2009;360:491-9 21. Mark W. Savannah E. H., Matthew D. M., et al Pediatric Perioperative Mortality in Kenya: A Prospective Cohort Study from 24 Hospitals. Perioperative Medicine 2019; XXX: 00-00

22. .T.E.F. Abbott1, T. Ahmad1, M.K. Phull et al The surgical safety checklist and patient outcomes after 
surgery: a prospective observational cohort study, systematic review and meta-analysis. British Journal of Anaesthesia, 120(1): 146e155 (2018)

23. Wang $\mathrm{H}$, Zheng $\mathrm{T}$, Chen $\mathrm{D}$, et al. Impacts of the surgical safety checklist on postoperative clinical outcomes in gastrointestinal tumor patients: A single-center cohort study. Medicine (Baltimore). 2019;98(28):e16418. doi:10.1097/MD.0000000000016418

24. Gavin J. Barnaby C. Reeves et.al Increased Mortality, Postoperative Morbidity, and Cost After Red Blood Cell Transfusion in Patients Having Cardiac Surgery. Circulation 2007; 116:2544-2552.

25. Kork, F., Felix B., Alexander K., et al. Association of Comorbidities With Postoperative In-Hospital Mortality A Retrospective Cohort Study. Medicine 2015; 94(8):e576)

26. J J W Roche, R T Wenn, O Sahota, et al Effect of comorbidities and postoperative complications on mortality after hip fracture in elderly people: prospective observational cohort study. BMJ. 2005; 331(7529): 1374.

27. Laurent G., Andrew W.D., Dana B. M., et al. Association between Intraoperative Blood Transfusion and Mortality and Morbidity in Patients Undergoing Non-cardiac Surgery. Anesthesiology 2011;(114), 283-292 28. Shaw RE, Johnson CK, Ferrari G, et al. Balanc- ing the benefits and risks of blood transfusions in patients undergoing cardiac surgery: a propensity-matched analysis. Interact Cardiovasc Thorac Surg. 2013;17(1):96102. doi:10.1093/icvts/ivt124

29. Elmi M, Mahar A, Kagedan D, et al. The impact of blood transfusion on perioperative outcomes following gastric cancer resection: an analysis of the American College of Surgeons National Surgical Quality Improvement Program database. Can J Surg. 2016;59(5):322-329. doi:10.1503/cjs.004016

30. Vincent JL, Baron JF, Reinhart K, et al. Anemia and blood transfusion in critically ill patients. JAMA. 2002; 288(12):1499-1507. doi:10.1001/ jama.288.12.1499

31. Robert H., Singletary BA., McMurtrie JT., et al Blood Transfusion and 30-Day Mortality in Patients With Coronary Artery Disease and Anemia Following Non-cardiac Surgery. JAMA SURGERY 2015; 151(2):1-8 DOI: 10.1001/jamasurg.2015;.3420 Surgery. 32. JP George, SN Myatra Blood Transfusion in the Critically Ill Patient - Bangladesh Critical Care Journal, 2018;6(1):40-46

33. Fecho K, Lunney AT, Boysen PG, Rock P, Norfleet EA. Postoperative mortality after inpatient surgery: Incidence and risk factors. Ther Clin Risk Manag. 2008;4(4):681-688. doi:10.2147/tcrm.s2735 